\title{
MINIPLATE REMOVAL FOLLOWING MAXILLOFACIAL TRAUMA: ROUTINE OR SYMPTOMATIC?
}

\author{
Lydia N. Melek* and Haytham Al Mahalawy **
}

\begin{abstract}
Background: The literature shows that hardware removal rates after fixation of maxillofacial fractures with miniplates are significant, as there are some needs for hardware removal in a number of patients who have been treated with metallic osteosynthesis devices.

Purpose: The purpose of the present study was to find the rates of and reasons for miniplates removal in patients who have been treated for maxillofacial fractures.

Patients and methods: The files of 103 patients who have been treated with open reduction and internal fixation with titanium miniplates were retrospectively revised. The number of patients who underwent miniplate removal was recorded. For each patient who has undergone miniplate removal; the indication for miniplate removal, the number of removed plates and the interval between plate placement and removal were recorded.

Results: 28 patients out of 103 patients have undergone miniplate removal with a total removal rate of $27.18 \%$. By excluding the pediatric population, the removal rate for the adult population alone was $9.6 \%$. Twenty cases were removed due to ongoing growth in children and teenagers $(71.43 \%)$, five cases for objective reasons $(17.85 \%)$ and three cases $(10.71 \%)$ due to subjective patient discomfort. A total of 51 plates were removed. Twelve plates $(23.5 \%)$ were removed from the mid-face and $39(76.47 \%)$ from the mandible.
\end{abstract}

Conclusion: The low rate of miniplate removal in this study shows that the routine removal of asymptomatic miniplates in adult population is not indicated.

KEYWORDS: Plate removal, Miniplates, Maxillofacial trauma

\section{INTRODUCTION}

Techniques for management of maxillofacial injuries have significantly developed in the previous years. These techniques have evolved from closed reduction with maxillomandibular fixation (MMF), to open reduction and internal fixation using wire osteosynthesis, to open reduction with either rigid or miniplate fixation ${ }^{[1]}$.

* Lecturer of Oral and Maxillofacial Surgery, Department of Oral and Maxillofacial Surgery, Faculty of Dentistry, Alexandria University.

** Oral and Maxillofacial Surgery Department, Alexandria University Hospital, Alexandria, Egypt. 
The literature shows that hardware removal rates after the fixation of maxillofacial fractures with miniplates are significant, as there are always some needs for hardware removal in a number of patients who have been treated with metallic plates. Some authors mentioned that about one of every five patients eventually undergoes plate removal due to objective or subjective reasons related to the hardware applied for treatment ${ }^{[2-5]}$. ANOTHER GROUP of AUthors As ChAmpy et al . (1978), CAWOOd (1985) and Albert \& Seligson (1996), have suggest ed the routine removal of miniplates three months after insertion in all patients ${ }^{[6-8]}$.

Low rates of plate removal have been reported in a number of studies in patients who have had their fractures treated with miniplate osteosynthesis, but it is difficult to obtain reliable conclusions regarding the indications for miniplate removal due to the small numbers included in these studies [1,9-10]. While O'Connell et al. (2009) in a 10 years retrospective study of 1247 titanium miniplates to determine the indications for their removal following osteosynthesis in maxillofacial trauma and orthognathic surgery, concluded that a low removal rate of $3 \%$ stipulates that the routine removal of asymptomatic titanium miniplates is not indicated $^{[11]}$.

Studies in which the authors have investigated plate removal rates per plate showed that removal rates have wide variation, ranging from $3.7 \%$ to $27.2 \%^{[3,12-13]}$. This variability in plate removal rates per plate is most likely explained by the fact that some surgeons prefer to remove only those plates that cause objective or subjective problems, while others prefer to remove all inserted plates ${ }^{[5]}$.

Although all the international oral and maxillofacial surgical units agrees that symptomatic plates must be removed, however, there is no consensus in the literature regarding the routine removal of asymptomatic miniplates, or this potential second operation for plate removal should be included in the overall patient treatment plan, or included in the patient consent form and in which situations. The purpose of the present study was to identify the rates of and reasons for miniplate removal in patients who have been treated for maxillofacial fractures.

\section{PATIENTS AND METHODS}

The present study included the files of 103 patients with maxillofacial trauma who have been treated with open reduction and internal fixation with titanium miniplates. Patients with significant medical conditions which may potentially compromise healing, such as diabetes mellitus, steroid therapy, immune disorders or bone disorders were excluded from this study. The follow-up period was 12 months.

From the patient records, data including gender, age, fracture type, and plate location were recorded. For each patient who has undergone plate removal, the indication for plate removal and number of plates removed was recorded. The reason for removal was based on the patient's report of symptoms, the surgeon's clinical assessment, and radiographic data. The interval between plate placement and removal was also calculated.

The indication for plate removal was selected from one of the following groups: (1) child with ongoing growth, (2) objective reason (i.e., wound dehiscence, infection, radiographic evidence of screw loosening or broken hardware, denture interference) and (3) subjective reason (i.e., cold sensitivity, palpability, pain in the absence of any clinical or radiographic evidence of infection or any other type of subjective discomfort)

\section{RESULTS}

Out of 103 cases treated by open reduction and internal fixation using titanium miniplates, 28 cases have undergone plate removal. The total plate removal rate was $27.184 \%$. The majority of patients were males (20 cases; $71.43 \%$ ). [Figure 1] 
The largest age groups were [1-9 years] accounting for $46.43 \%$ and [10-19 years] accounting for $25 \%$. Patients with age range [30-39 years] accounted for $10.71 \%$, while those from [50-59 years] for $7.14 \%$. Each of the other age groups represented only $3.57 \%$ of the total number of cases. [Figure 2]

Of the 28 cases who have undergone plate removal, 20 cases were due to ongoing growth in children and teenagers $(71.43 \%), 5$ cases for

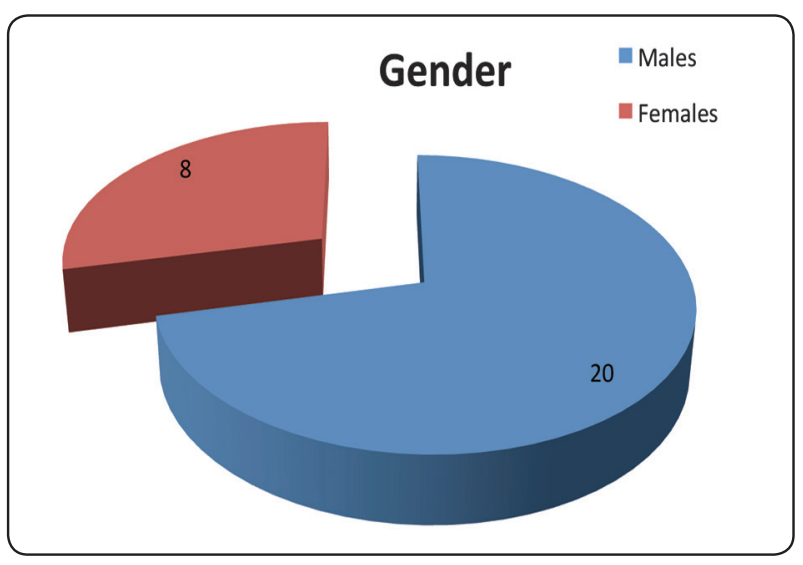

Fig. (1) Gender distribution of plate removal cases

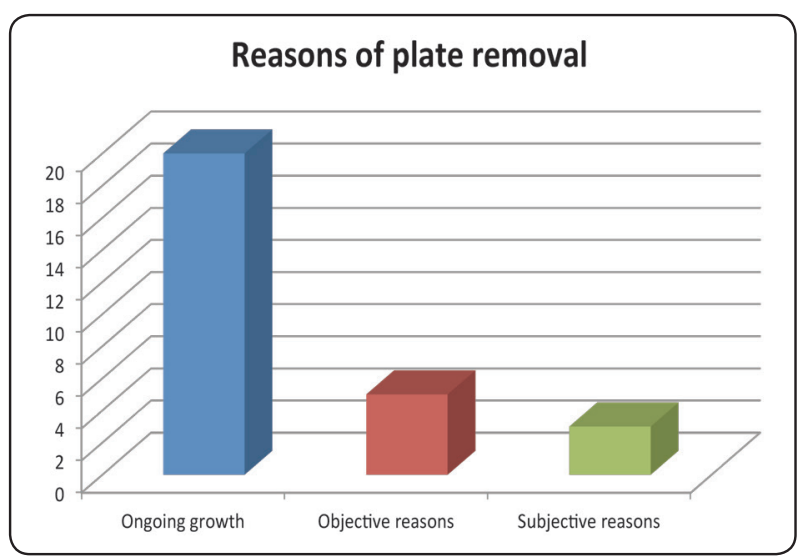

Fig. (3) Percentage of different reasons for plate removal in the study sample objective reasons (17.85\%) including 3 cases of infection (Pain, swelling, fistula, pus formation or any combination of these were summed up under the term infection), one case of denture interference and one case of hardware failure. The remaining 3 cases $(10.71 \%)$ were removed due to subjective patient discomfort. [Figure 3]

A total of 51 plates were removed. Twelve plates $(23.5 \%)$ were removed from the mid-face and 39 $(76.47 \%)$ from the mandible. [Figure 4]

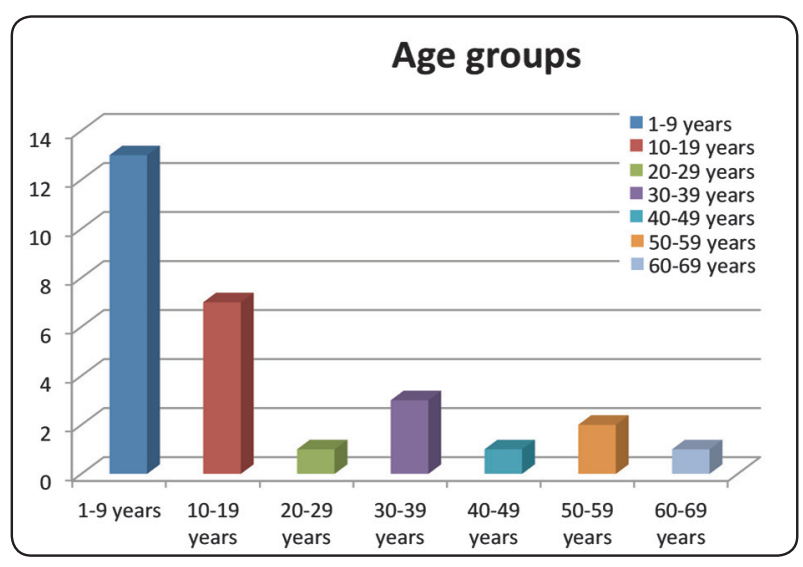

Fig. (2) Distribution of the plate removal cases among the different age groups

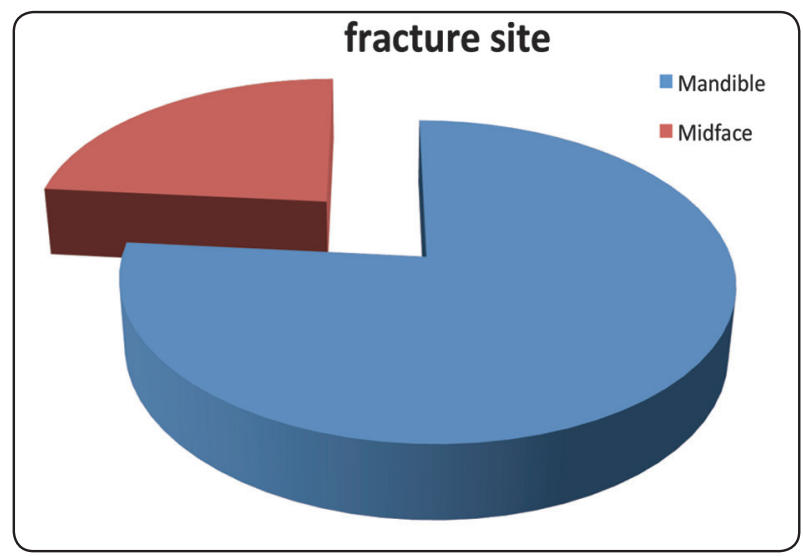

Fig. (4) distribution $\mathrm{f}$ plate removal cases according to fracture site 


\section{DISCUSSION}

There is still no consensus regarding the need for routine removal of asymptomatic titanium miniplates in the maxillofacial skeleton. There are two opinions; some authors recommend routine removal, while others recommend retention unless clinical conditions indicate their removal, so that, the prospective management of the inserted miniplates remains controversial. Nowadays, most surgical units around the world do not remove miniplates following bony union. However, some units in central Europe and some in the UK have advocated the routine removal of miniplates ${ }^{[14-16]}$.

At their symposium held in the Netherlands (1991), the Strasbourg Osteosynthesis Research Group (SORG) provided the following recommendations: "A plate which is intended to assist the healing of bone becomes a non-functional implant once this role is completed. It may then be regarded as a foreign body. While there is no clear evidence to date that a plate causes actual harm, our knowledge remains incomplete. It is therefore not possible to state with certainty that an otherwise symptomless plate, left in situ, is harmless. The removal of a non-functional plate is desirable provided that the procedure does not cause undue risk to the patient" ${ }^{\text {"[17] }}$. However, most studies suggest that the routine removal of asymptomatic miniplates is not mandatory and it was only performed when symptoms dictated ${ }^{[2,15,18-19]}$.

Matthew and Frame (1999) in a pilot study to determine the policy of 23 consultant oral and maxillofacial surgeons towards removal of miniplates after jaw fractures had healed estimated that the total percentage of miniplates removal rates was ranged between $5 \%$ and $40 \%{ }^{[14]}$. This is in agreement with our results where the total plate removal rate was $27.18 \%$.

The policy in our department is to routinely remove all metallic plates in children and teenagers in whom the growth potential is still ongoing, and this explains why these represent the largest age groups in the present study. In adults and old age, we remove only symptomatic plates whether for objective reasons as determined by the surgeon's clinical and radiographic assessment or due to reported discomfort by the patient.

In this study, 28 patients out of 103 patients have undergone plate removal with a total removal rate of $27.18 \%$, from these 28 cases, 20 cases were due to ongoing growth in children and teenagers. By excluding these age group, so that only 8 patients out of 83 patients in the adult population have undergone plate removal with a removal rate of $9.6 \%$. This finding is in agreement with other studies which reported plate removal rates of $3 \%$ $16 \%{ }^{[4,11,13,15,18]}$.

In the current study, the most common reasons for plate removal in adults were due to objective reasons including infection, denture interference and hardware failure. The most common objective reason in this study was due to infection which accounted for 3 patients out of 5 patients. This agrees with Mosbah et al. (2003), who stated that the commonest indications for plate removal in their study were infection and/or wound dehiscence ${ }^{[15]}$.

The subjective reasons for miniplate removal in adults in the current study were the patients' request and plates being palpable causing patient discomfort. This is specifically related to the thin soft tissue coverage in the mid-face and the upper third of the face particularly the peri-orbital region due to the greater awareness of plates in these areas. However, no patients in our study complained of temperature sensitivity, mostly due to the moderate climate in Egypt.

In this series, the average duration between plate insertion and removal was 5.59 month. This is in accordance with other studies which reported removal time between 3 to 14 months after treatment ${ }^{[2,4]}$. Mosbah et al. (2003) in their study have also found that $75 \%$ of those patients requiring 
plate removal had undergone this second operation within 6 months postoperatively ${ }^{[15]}$.

It is usually easy to perform plate removal four to six months after fracture treatment, but years later it sometimes becomes much more difficult, especially in young patients in whom the plates are often covered by bone. That is why we usually undertake metallic plate removal in children and teenagers between 4 and 6 months post-treatment to avoid plate and screws becoming hidden by the rapidly growing bone.

In this study, the number of plates removed from the mandible exceeded those removed from the middle third of the face, which is in agreement with Mosbah et al. (2003) ${ }^{[15]}$, Rallis et al. (2006) ${ }^{[13]}$, Bakathir et al. (2008) ${ }^{[4]}$ and O'Connell et al. (2009) ${ }^{[11]}$, where patients with mandibular fractures formed the significant group among those undergoing plate removal after fracture treatment.

Thoren et al. (2010), in their study have observed that the mandible is more susceptible to complications and to a potential need for plate removal. This may be explained by the fact that miniplates deals only with tensile stress. The repeated loading during mastication and the muscular forces during the continuous mandibular movements may lead to the deterioration of the rigidity of miniplates if they are not properly placed at the ideal lines of osteosynthesis. These factors could lead to the potential loosening or breaking of the hardware, instability, non-union, or infection ${ }^{[5]}$.

So, our recommendations to minimize the need for a second operation for plate removal are to use resorbable plates in young patients and the nonstress bearing regions (as the middle third) in adults, and for mandibular factures in adults, a reduction in the complication rate (and consequently reduction in the plate removal rate) may be achieved with the use of more rigid fixation devices as 3-dimensional plates and locking miniplates which provide a significantly higher stability than conventional miniplates.

\section{CONCLUSIONS}

The low rate of miniplate removal in this study suggests that the routine removal of asymptomatic miniplates in adult population is not indicated.

Ethical considerations: this study was performed in accordance with the regulations of the Research Ethics Committee, Faculty of Dentistry, Alexandria University, Egypt.

\section{REFERENCES}

1. Haug RH. Retention of asymptomatic bone plates used for orthognathic surgery and facial fractures. J Oral Maxillofac Surg 1996;54:611-7.

2. Islamoglu K, Coskunfirat OK, Tetik G, Ozgentas HE. Complications and removal rates of miniplates and screws used for maxillofacial fractures. Ann Plast Surg 2002;48:265-8.

3. Nagase DY, Courtemanche DJ, Peters DA. Plate removal in traumatic facial fractures: 13-year practice review. Ann Plast Surg 2005;55:608-11.

4. Bakathir AA, Margasahayam MV,Al-Ismaily MI. Removal of bone plates in patients with maxillofacial trauma: a retrospective study. Oral Surg Oral Med Oral Pathol Oral Radiol Endod 2008;105:e32-7.

5. Thoren H, Snall J, Kormi E, Lindqvist C, SuominenTaipale L, Tornwall J. Symptomatic plate removal after treatment of facial fractures. J Craniomaxillofac Surg 2010;38:505-10.

6. Champy M, Lodde JP, Schmitt R, Jaeger JH, Muster D. Mandibular osteosynthesis by miniature screwed plates via a buccal approach. J Maxillofac Surg 1978;6:14-21.

7. Cawood JI. Small plate osteosynthesis of mandibular fractures. Br J Oral Maxillofac Surg 1985;23:77-91.

8. Alpert B, Seligson D. Removal of asymptomatic bone plates used for orthognathic surgery and facial fractures. J Oral Maxillofac Surg 1996;54:618-21.

9. Nakamura S, Takenoshita Y, Oka M. Complications of miniplate osteosynthesis for mandibular fractures. J Oral Maxillofac Surg 1994;52:233-8; discussion 8-9.

10. Rix L, Stevenson AR, Punnia-Moorthy A. An analysis of 80 cases of mandibular fractures treated with miniplate osteosynthesis. Int J Oral Maxillofac Surg 1991; 20:337-41. 
11. O’Connell J, Murphy C, Ikeagwuani O, Adley C, Kearns $\mathrm{G}$. The fate of titanium miniplates and screws used in maxillofacial surgery: a 10 year retrospective study. Int J Oral Maxillofac Surg 2009;38:731-5.

12. Murthy AS, Lehman JA, Jr. Symptomatic plate removal in maxillofacial trauma: a review of 76 cases. Ann Plast Surg 2005;55:603-7.

13. Rallis G, Mourouzis C, Papakosta V, Papanastasiou G, Zachariades N. Reasons for miniplate removal following maxillofacial trauma: a 4-year study. J Craniomaxillofac Surg 2006;34:435-9.

14. Matthew IR, Frame JW. Policy of consultant oral and maxillofacial surgeons towards removal of miniplate components after jaw fracture fixation: pilot study. Br J Oral Maxillofac Surg 1999;37:110-2.
15. Mosbah MR, Oloyede D, Koppel DA, Moos KF, Stenhouse D. Miniplate removal in trauma and orthognathic surgery - a retrospective study. Int J Oral Maxillofac Surg 2003;32:148-51.

16. Thoren H, Snall J, Hallermann W, Kormi E, Tornwall J. Policy of routine titanium miniplate removal after maxillofacial trauma. J Oral Maxillofac Surg 2008; 66:1901-4.

17. Strasbourg Osteosynthesis Group. Consensus statement. The 3rd SORG meeting, Volendam, the Netherlands1991.

18. Bhatt V, Chhabra P, Dover MS. Removal of miniplates in maxillofacial surgery: a follow-up study. J Oral Maxillofac Surg 2005;63:756-60.

19. Bhatt V, Langford RJ. Removal of miniplates in maxillofacial surgery: University Hospital Birmingham experience. J Oral Maxillofac Surg 2003;61:553-6. 